\section{Microcefalia primária autossômica recessiva em três famílias pernambucanas: aspectos clínicos e moleculares}

\section{Autosomal recessive primary microcephaly in three families from Pernambuco: clinical and molecular aspects}

Gabriela F. Leal 1

Serviço de Genética Médica. Instituto Materno-Infantil de Pernambuco, IMIP. Rua dos Coelhos, 300. Recife, Pe, Brasil, CEP: 50.070-550. E mail: gferraz@nlink.com.br

\begin{abstract}
Objectives: to describe the clinical findings in three families from Pernambuco with autosomal recessive primary microcephaly, and the linkage analysis in one of them (family 2).

Methods: three consanguineous families from Pernambuco, not related one to another and with primary microcephaly, were studied. The genealogical data and the clinical history of the affected individuals were obtained from their parents and other family members. All the affected subjects, almost all their normal siblings, and their parents were clinically examined. Genomic DNA from the microcephalic persons of family 2 and from their parents was used in PCR (polimerase chain reaction) reactions with primers designed to amplify microsatellite markers linked to the known autosomal recessive primary microcephaly loci. Amplified markers were electrophoresed and analysed.

Results: in the three families, all the affected subjects presented a small head circumference with accompanying mental retardation, and only one patient (of family 3) showed other neurological problems. None of the microcephalic individuals had dysmorphic features. Molecular studies on family 2 revealed that the microcephaly in this family was not linked to any of the already known autosomal recessive primary microcephaly loci.

Conclusion: at least one more locus associated with autosomal recessive primary microcephaly exists and awaits discovery.
\end{abstract}

Key words Microcephaly, Linkage (Genetics)

\section{Resumo}

Objetivos: descrever os aspectos clínicos de três famílias pernambucanas com microcefalia primária autossômica recessiva e as análises de ligação em uma delas (família 2).

Métodos: três famílias consangüineas pernambu canas, não relacionadas biologicamente, com micro cefalia primária, foram estudadas. Os heredogramas e a história clínica dos afetados foram construídos com base em informações obtidas de seus pais e outros parentes. O exame físico foi realizado em todos os afetados, seus genitores e na quase totalidade dos irmãos normais dos afetados. O DNA genômico dos afetados da família 2 e de seus pais foi usado em reações de PCR (polimerase chain reaction) com primers elaborados para amplificar marcadores microssatélites ligados aos locos já conhecidos de microcefalia primária autossômica recessiva. Os marcadores amplificados foram submetidos a eletro forese e seus alelos analisados.

Resultados: nas três familias, os afetados apresen tavam perímetro cefálico muito reduzido acompanhado de retardo mental e apenas uma paciente (da família 3) manifestava outras alterações neurológicas, mas sem dismorfias associadas. Estudos moleculares demonstraram que a microcefalia, na família 2, não apresentava ligação com nenhum dos locos associados à microcefalia primária autossômica recessiva já conhecidos.

Conclusões: pelo menos mais um gene associado à microcefalia primária autossômica recessiva existe e aguarda identificação.

Palavras-chave Microcefalia, Ligação (Genética) 


\section{Introdução}

Considera-se que um indivíduo apresenta microcefalia quando a medida de seu perímetro cefálico situa-se mais de três desvios-padrões (DP) abaixo da média populacional para idade e sexo. ${ }^{1} \mathrm{~A}$ microcefalia é um sinal clínico encontrado em vários distúrbios com etiologia ambiental e/ou genética, podendo estar acompanhado de outros defeitos morfológicos (forma sindrômica) ou não (microcefalia nãosindrômica). Hipóxia perinatal, infecções congênitas (tais como rubéola, citomegalovirose, toxoplasmose e herpes-virose tipo 2), exposição intra-uterina a radiação ionizante e a drogas (como álcool e hidantoína), e fenilcetonúria materna são algumas das causas ambientais de microcefalia.2,3 A microcefalia geneticamente determinada pode resultar de alterações monogênicas, anomalias cromossômicas ou distúrbios multifatoriais. 4

A microcefalia primária autossômica recessiva (MPAR) é uma das formas de microcefalia genética. Os indivíduos afetados apresentam redução do perímetro cefálico - como conseqüência de uma diminuição na espessura do córtex cerebral - associado à retardo mental, não se observando dismorfias, malformações ou outras alterações neurológicas significativas. 4 A MPAR é geneticamente heterogênea, com seis locos já mapeados: MPAR1 em 8p23,5 MPAR2 em 19q13,6 MPAR3 em 9q34,7 MPAR4 em 15q15-q21,8 MPAR5 em 1q319,10 e MPAR6 em 13q12.2.11

Neste trabalho, relatamos os aspectos clínicos de três famílias pernambucanas com MPAR e os resultados de análises de ligação realizadas em uma delas.

\section{Métodos}

As três famílias estudadas não são biologicamente relacionadas. A família 1 é originária do sertão pernambucano; a 2, do Agreste e a família 3 é proveniente da região metropolitana do Recife. As figuras 1, 2 e 3 representam os heredogramas dessas famílias. As informações genealógicas foram obtidas com a colaboração de vários membros das famílias, e exame físico foi realizado em todos os afetados, seus genitores e na quase totalidade dos irmãos dos afetados. Análise cromossômica com bandeamento G (400 bandas), exame oftalmológico, tomografia computadorizada crânio-encefálica, eletroencefalograma e testes para infecções congênitas foram realizados em diversos pacientes das três famílias.

Figura 1

Heredograma da família 1

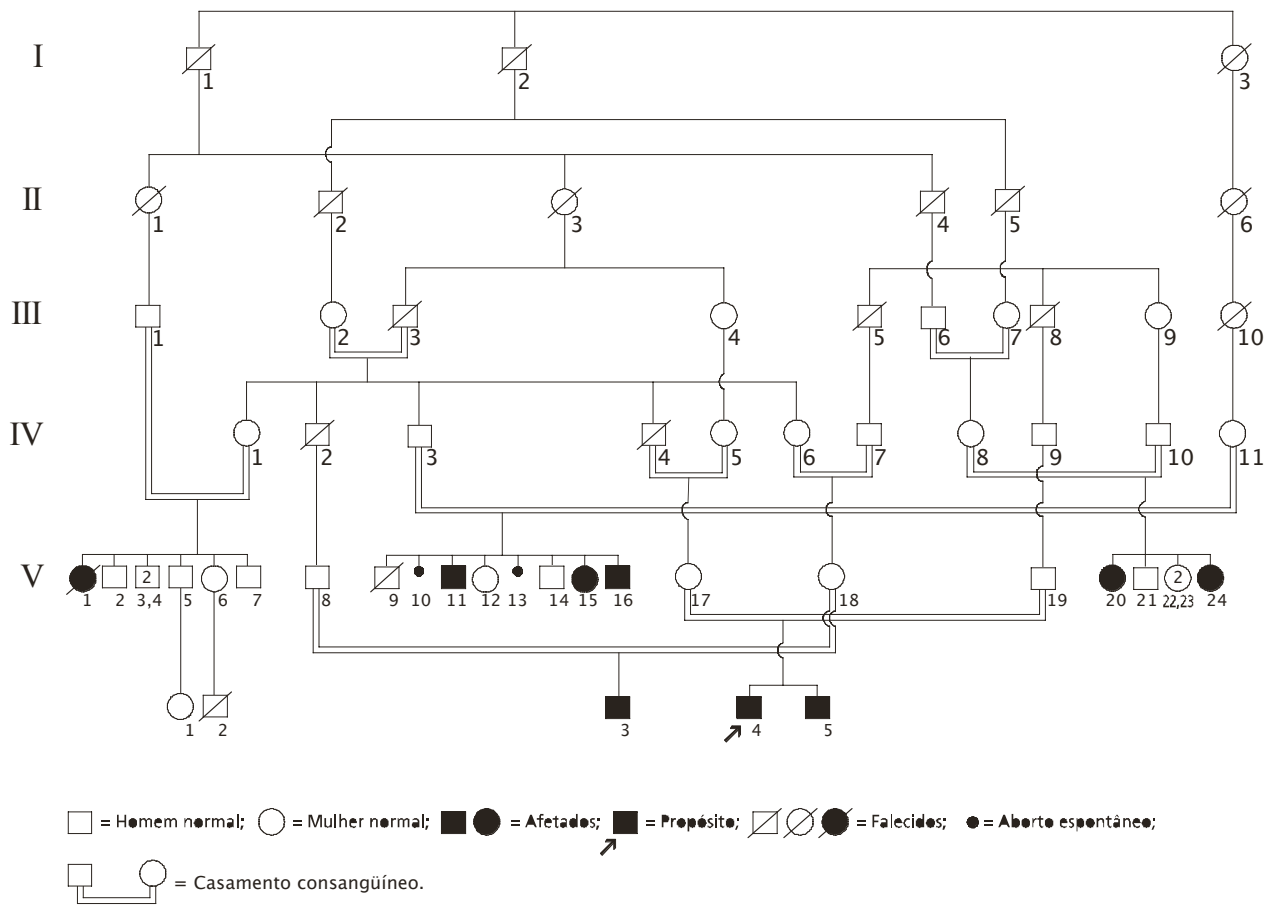


I

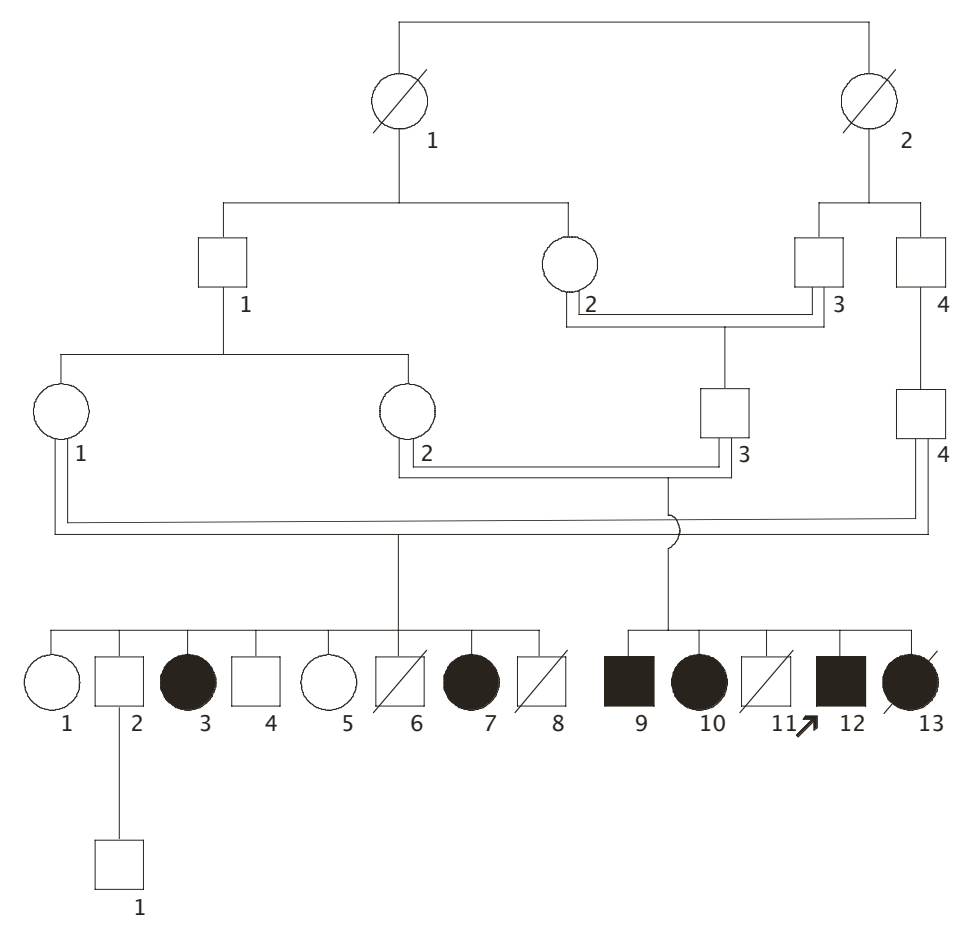

Figura 3

Heredograma da família 3.

I

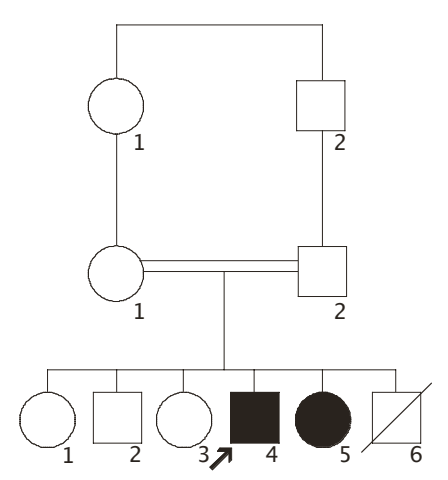

Os estudos de ligação foram realizados com o DNA genômico dos afetados da família 2 e de seus pais. O DNA, obtido a partir de leucócitos do sangue periférico, foi usado em reações de PCR (polimerase chain reaction) com primers marcados com fluorescência e elaborados para amplificar marcadores microssatélites ligados aos locos MP1-MP6. Os marcadores amplificados foram submetidos à eletroforese em seqüenciador ABI Prism 377 (Applied Biosystems) e a análise de tamanho dos seus alelos foi realizada com os programas de computador ABI Prism Genescan e Genotyper (versão 1.1.1) (Applied Biosystems).

\section{Resultados}

\section{Estudos clínicos}

A família 1 continha oito afetados vivos (cinco do sexo masculino e três do feminino), com idades entre quatro e 27 anos, distribuídos em quatro irmandades 
(Figura 1). Na família 2, havia cinco indivíduos microcefálicos vivos (dois masculinos e três femininos), com idades variando de 15 a 25 anos e distribuídos em duas irmandades (Figura 2). $\mathrm{Na}$ família 3, eram afetados um rapaz e uma moça com 16 e 15 anos de idade respectivamente (Figura 3). Todos os afetados das três famílias nasceram a termo, não havendo intercorrências dignas de nota durante as gestações. Quando examinados, os pacientes das famílias 1 e 2 apresentavam medidas de perímetro cefálico com 7-10 e 4-6 DP abaixo da média respectivamente, e, em ambas as famílias, o retardo mental era moderado. Os adultos e adolescentes afetados não sabiam ler nem escrever, mas falavam frases simples e tomavam banho, vestiamse e alimentavam-se sozinhos.

Na família 3, o indivíduo III-4 tinha medida de perímetro cefálico com $6 \mathrm{DP}$ abaixo da média e retardo mental moderado: conhecia o alfabeto mas não aprendeu a ler/escrever, apesar de freqüentar escola desde os seis anos de idade. Sua irmã afetada (III-5) apresentava perímetro cefálico com 8 DP abaixo da média e deficiência mental grave: não falava palavras intelegíveis, nem tinha controle esfincteriano. Os irmãos III-1, III-2 e III-3 apresentavam perímetro cefálico com 2-3 DP abaixo da média e nível intelectual variável - III-1 era intelectualmente normal, enquanto III-2 e III-3 manifestavam retardo leve (ambos freqüentaram escola desde os seis anos de idade, mas liam precariamente e foram reprovados várias vezes). Todos os afetados das famílias 1 e 2, assim como o afetado III-4 da família 3, eram eumórficos, com estatura normal e sem outros problemas neurológicos além do déficit intelectual. A adolescente afetada III-5 da família 3 também era eumórfica, mas apresentava espasticidade generalizada. Os genitores de todos os afetados eram normocéfalos e intelectualmente normais. Análise cromossômica, exame oftalmológico, eletroencefalograma e testes para infecções congênitas não revelaram alterações. A tomografia computadorizada crânio-encefálica apenas confirmou a presença de microcefalia, não tendo sido observadas outras anormalidades.

\section{Estudos de ligação}

A análise de tamanho dos alelos dos marcadores microssatélites ligados aos locos MP1-MP6 mostrou que nenhum desses seis locos representavam regiões de homozigose na família 2, excluindo-se assim a possibilidade de que a microcefalia, nessa família, fosse causada por mutações em homozigose em gene localizado em um desses seis locos.

\section{Discussão}

Descrevemos aqui três famílias pernambucanas com MPAR. Todos os afetados apresentavam redução importante do perímetro cefálico acompanhada de retardo mental, na ausência de dismorfias/malformações, e apenas uma paciente (III-5/família 3) manifestava outros problemas neurológicos. Além disso, apresentavam desenvolvimento motor normal (com a exceção de III-5/família 3), eram bemhumorados e tinham convívio social fácil, o que está de acordo com a observação de que, na MPAR, as habilidades sociais parecem bem menos comprometidas do que as cognitivas.

Outras características encontradas que ajudam a firmar o diagnóstico dessa anomalia são a presença de consangüinidade, a ausência de um fator ambiental causador de microcefalia, a história de gestação e parto sem intercorrências, e o achado, na tomografia crânio-encefálica, de um cérebro simetricamente pequeno mas sem alterações estruturais.4,12

Os estudos moleculares que foram realizados com a família 111 - a primeira família brasileira com MPAR analisada molecularmente - resultaram no mapeamento do sexto loco gênico determinante dessa condição na região cromossômica 13q12.2. O primeiro gene foi mapeado em 1998 em uma família paquistanesa 5 e, posteriormente, outros quatro foram identificados em outras famílias. ${ }^{6-10}$ Os genes de MPAR1 e MPAR5 já foram clonados. A MPAR1 é causada por mutações em homozigose no gene microcefalina, que apresenta altos níveis de expressão nas paredes dos ventrículos laterais, onde células progenitoras dividem-se e originam neurônios que migram para formar o córtex cerebral.13 Em MPAR5, mutações em homozigose ocorrem no gene ASPM (abnormal spindle-like microcephaly associated), envolvido na formação e no funcionamento do fuso mitótico nos neuroblastos da fase embrionária. Alterações da proteína codificada por esse gene impedem que neuroblastos em divisão celular progridam além da metáfase, prejudicando, assim, o desenvolvimento do sistema nervoso central. 14

Análises de ligação com a família 2, ao sugerirem que a microcefalia, nessa família, não era causada por mutações em nenhum dos seis locos mapeados previamente, levantam a possibilidade de existência de um novo gene associado à MPAR aguardando identificação. Considerando-se a complexidade do desenvolvimento do cérebro, um processo que envolve um balanço da proliferação, migração e apoptose neuronais, ${ }^{15}$ já era esperado que a microcefalia primária apresentasse importante 
heterogeneidade genética, entretanto essa heterogeneidade de locos não é acompanhada de uma heterogeneidade fenotípica correspondente, porquanto todas as famílias em que se mapearam os diferentes locos apresentavam quadros clínicos bastante semelhantes, não sendo possível, com base apenas em dados clínicos, diferenciar-se as seis formas entre si. 16

Na família 3, o paciente III-4 apresentava quadro típico de MPAR, mas sua irmã afetada manifestava retardo neuropsicomotor grave com espasticidade generalizada, o que viabiliza a hipótese de patologia associada, ainda que não identificada. Analisando 48 casos (19 familiais, distribuídos em nove famílias, e 29 casos isolados) de microcefalia não-sindrômica com provável modo de herança autossômico recessivo, Tolmie et al. 17 observaram que sete dos casos isolados e cinco das nove famílias com mais de um afetado apresentavam microcefalia acompanhada de espasticidade e/ou crises convulsivas, e que a severidade da microcefalia e da espasticidade variava entre as famílias e também entre os irmãos afetados. Contudo, essas famílias, assim como a família 3 aqui descrita, não foram estudadas com técnicas de DNA. A análise molecular dessas famílias poderia esclarecer se, eventualmente, genes determinantes de microcefalia estariam etiologicamente implicados na ocorrência de manifestações neurológicas adicionais. Outro aspecto relevante relativo à família 3 é o fato de que os irmãos III-1, III-2 e III-3 apresentavam medidas de perímetro cefálico nos limites inferiores de normalidade e dois deles (III-2 e III-3) exibiam deficiência mental leve, enquanto os perímetros cefálicos de seus genitores situavam-se em torno da média populacional. Assim, julgamos pertinente questionar se os fenótipos desses três indivíduos representam manifestações suaves de mutação em homozigose em um dos genes determinantes de microcefalia primária, ou manifestações do gene mutante em heterozigose. Essa questão poderia ser elucidada com a análise molecular dessa família, que ainda não foi realizada.

Casais com crianças portadoras de microcefalia são freqüentemente encaminhados aos serviços de genética médica para avaliação diagnóstica e aconselhamento, e uma parcela substancial dessas crianças consiste de casos esporádicos de microcefalia isolada. Não é surpreendente que esses casos representem problemas especiais para o aconselhamento genético. Havendo apenas uma criança afetada na família, sem anomalias associadas que permitam o diagnóstico de síndrome específica e sem consangüinidade parental, torna-se difícil discernir se a causa da microcefalia é genética ou ambiental. O mapeamento e a caracterização molecular dos genes causadores de microcefalia, e a identificação de seus produtos e funções correspondentes, constituem uma contribuição extraordinária à compreensão da patogênese da microcefalia. E esses conhecimentos poderão ser utilizados no diagnóstico pré-natal, na detecção de heterozigotos, no diagnóstico e - possivelmente no futuro - tratamento dos afetados.

\section{Agradecimentos}

Agradecemos às famílias estudadas pela confiança e colaboração, e à CAPES (Coordenação de Aperfeiçoamento de Pessoal de Nível Superior) e à FACEPE (Fundação de Amparo à Ciência e Tecnologia de Pernambuco) pelo suporte financeiro. As análises moleculares foram realizadas na Unidade de Medicina Molecular do Hospital St James's (Universidade de Leeds, Inglaterra) sob a supervisão dos Drs. Christopher G. Woods e Emma Roberts, a quem dispensamos agradecimentos especiais. 


\section{Referências}

1. Böök JA, Schut JW, Reed SC. A clinical and genetical study of microcephaly. Am J Ment Defic 1953; 57: 637- 60.

2. Ross JJ, Frias JL. Microcephaly. In: Vinken PJ, Bruyn GW, editors. Congenital malformations of the brain and skull. Amsterdam: Elsevier Holland Biom edical; 1977. p. 507-24.

3. Warkany J, Lemire RJ, Cohen MM. Microcephaly. In: Warkany J, Lemire RJ, Cohen MM, editor s. Mental retardation and congenital malformations of the central nervous system. Chicago: Year Book Medical Publishers; 1981. p. 13-40.

4. Baraitser M. Microcephaly. In: Baraitser M, editor. The genetics of neurological disorders. Oxford: Oxford University Press; 1997. p. 17-38.

5. Jackson AP, McHale DP, Campbell DA, Jafri H, Rashid Y, Mannan J, Karbani G, Corry P, Levene MI, Mueller RF, Markham AF, Lench NJ, Woods CG. Primary autosomal recessive microcephaly ( $\mathrm{MCPH} 1$ ) maps to chromosome 8p22-pter. Am J Hum Genet 1998; 63: 541-6.

6. Roberts E, Jackson AP, Carradice AC, Deeble VJ, Mannan J, Rashid Y, Jafri H, McHale DP, Markham AF, Lench NJ, Woods CG. The second locus for autosomal recessive primary microcephaly (MCPH2) maps to chromosome 19q13.1-13.2. Eur J Hum Genet 1999; 7: 815-20.

7. Moynihan L, Jackson AP, Roberts E, Karbani G, Lewis I, Corry P, Turner G, Mueller RF, Lench NJ, Woods CG. A third novel locus for primary autosomal recessive microcephaly maps to chromosome 9q34. Am J Hum Genet 2000; 66: 724-7.

8. Jamieson CR, Govaerts C, Abramowicz MJ. Primary autosomal recessive microcephaly: homozygosity mapping of MCPH4 to chromosome 15. Am J Hum Genet 1999; 65: 1465-9.

9. Pattison L, Crow YJ, Deeble VJ, Jackson AP, Jafri H, Rashid Y, Roberts E, Woods CG. A fifth locus for primary autosomal recessive microcephaly maps to chromosome 1q31. Am J Hum Genet 2000; 67: 157 8-80.
10. Jamieson CR, Fryns J-P, Jacobs J, Matthijs G, Abramowicz MJ. Primary autosomal recessive microcephaly: MCPH5 maps to 1q25-q32. Am J Hum Genet 2000; 67: 1575- 7.

11. Leal GF, Roberts E, Silva EO, Costa SMR, Hampshire DJ, Woods CG. A novel locus for autosomal recessive primary microcephaly maps to $13 q 12.2$. J Med Genet 2003; 40: 540-2.

12. Qazi QH, Reed E. A problem in diagnosis of primary versus secondary microcephaly. Clin Genet 1973; 4: 46- 52.

13. Jackson AP, Eastwood H, Bell SM, Adu J, Toomes C, Carr IM, Roberts E, Hampshire DJ, Crow YJ, Mighell AJ, Karbani G, Jafri H, Rashid Y, Mueller RF, Markham AF, Woods CG. Identification of microcephalin, a protein implicated in determining the size of the human brain. Am J Hum Genet 2002; 71: 136-42.

14. Bond J, Roberts E, Mochida GH, Hampshire DJ, Scott S, Askham JM, Springell K, Mahadevan M, Crow YJ, Markham AF, Walsh CA, Woods CG. ASPM is a major determinant of cerebral cortical size. Nat Genet 2002; 32: 316-20.

15. Vaccarino FM, Schwartz ML, Raballo R, Nilsen J, Rhee J, Zhou M, Doetschman T, Coffin JD, Wyland JJ, Hung Y T. Changes in cerebral cortex size are governed by fibroblast growth factor during embryogenesis. Nat Neurosci 1999; 2: 246-53.

16. Roberts E, Hampshire DJ, Pattison L, Springell K, Jafri H, Corry P, Mannon J, Rashid Y, Crow Y, Bond J, Woods CG. Autosomal recessive primary microcephaly: an analysis of locus heterogeneity and phenotypic variation. J Med Genet 2002; 39: 718-21.

17. Tolmie JL, McNay M, Stephenson JBP, Doyle D, Connor JM. Microcephaly: genetic counselling and antenatal diagnosis after the birth of an affected child. Am J Med Genet 1987; 27: 583-94.

Recebido em 1 de julho de 2004

Versão final apresentada em 8 de março de 2005

Aprovado em 22 de abril de 2005 